\title{
Uplink-Downlink Scheduling Algorithm for Improving Quality of Service in Small Cell Network \\ ${ }^{* 1}$ Cuminious Okram, ${ }^{2}$ Veena Gulhane \\ ${ }^{1}$ PG Student, GHRCE, ${ }^{2}$ Professor, GHRCE \\ *Email: cuminiousokram@gmail.com,veena.gulhane@raisoni.net
}

Received: 09 ${ }^{\text {th }}$ July 2018, Accepted: 14 ${ }^{\text {th }}$ August 2018, Published: 31 ${ }^{\text {st }}$ August 2018

\begin{abstract}
Mobile communication is emerging rapidly with the passages of time along with large number of user increasing day by day. A lot of work on QoS is going on but still different issues are coming up. Due to nonavailability of the radio channels many data packet gets dropped. Since the resources are limited, it is important to utilize the resources properly to provide better service to every customer. In this paper we present mobile network based small cell network with uplink and downlink scheduling algorithm. The network performance is evaluated in terms of its quality of service parameters such as throughput, delay and packet delivery ratio. After implementing uplink and downlink scheduling algorithm on MANET the resulting quality of service parameters show significant improvement as compared to simple small cell network. This system is designed on Network Simulator (NS2).
\end{abstract}

Keywords: Mobile Ad-hoc Network, UplinkDownlink Scheduling, Small Cell Network, Quality of Service

\section{Introduction}

A mobile ad-hoc network is made up from a group of MANET routers. These routers put in order and support sending the way structure among themselves. As the net approved design router, MR may made joined group of hard growths. The mobile node transmits the signal within its transmission range as shown in figure 1. In MANET the mobile nodes are present in the small cell networks. The position of the mobile nodes goes on changing continuously hence the topology of the mobile network also frequently changes. Small cell help in bringing out the connectivity in remote areas where terrestrial satellite connection is very slow. But small cell itself is not sufficient. To solve this, scheduling is one of the solutions to use most of the resources [1].

The advantages of small cell network are lower delay, in-building coverage, etc. Figure 2 shows the architecture of small cell network which consist of number of mobile nodes with base stations. Here uplink tends to link from mobile station to base station and downlink means base station to mobile station.
Our algorithms provide better uplink and downlink connectivity in between source to destination. By using uplink and downlink scheduling algorithm, the results shows that our approach provides a significant improvement in throughput, delay and packet delivery ratio.

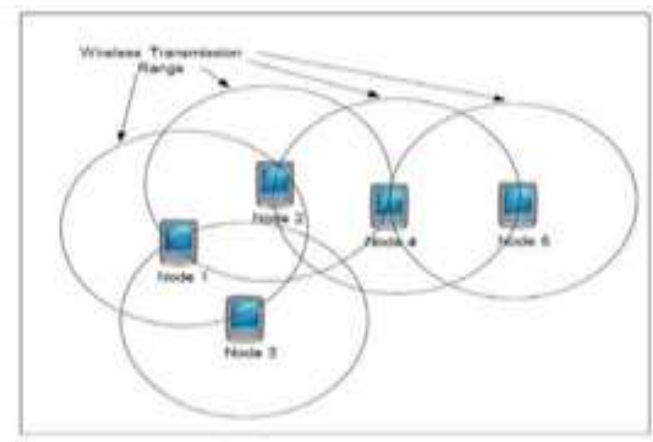

Fig.1. MANET Nodes and their Transmission

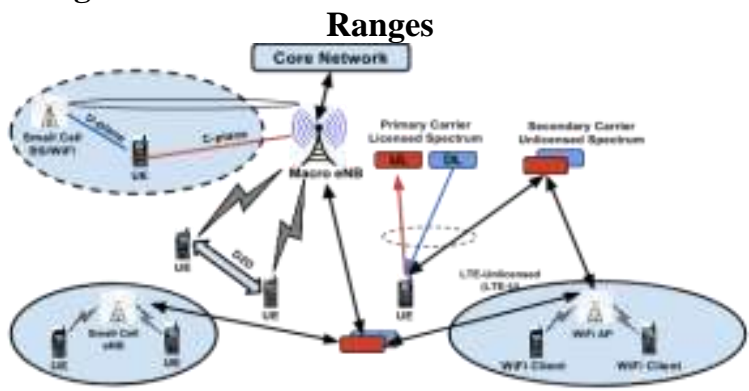

Fig.2. Small Cell Network Architecture

The remaining portion of the paper is written as Section I described the previous work based on scheduling and quality of service, Section II describes the proposed algorithm and simulation parameter, section III explain the detailed implementation processed and the results are presented in Section IV.

Related Work

Different algorithm and different parameter of Quality of service are considered so that it can be improved to provide best service to the ever increasing user. Some algorithm work best with uplink only and some work best with downlink only.

(A). Joint UL-DL scheduling is explained for LTE based on QoS. The technique refer by this algorithm is carrier aggregation which in turn help in increasing throughput [2] 
(B). In paper [3], algorithm based on uplink scheduling is purposed. The purposed system helps in improvement in quality of service by providing algorithm in the uplink data transmission with presence of LTE and small sell network [3]

(C). Scheduling based algorithm is discussed and provide different approaches to enhance uplink data transmission by the use of scheduling concept. The proposed algorithm is useful in LTE network. It tests its concept by applying to different user and calculated the result. Transmission of data is monitored with SNR. It helps in scheduling of time and packet [4].

\begin{tabular}{|c|c|c|}
\hline $\begin{array}{l}\text { Proposed } \\
\text { Method }\end{array}$ & $\begin{array}{l}\text { Focused } \\
\text { Area }\end{array}$ & $\begin{array}{l}\text { Advantages and } \\
\text { Drawbacks }\end{array}$ \\
\hline Novel algorithm & $\begin{array}{l}\text { Support } \\
\text { Quality of } \\
\text { Service (QoS) } \\
\text { aware uplink } \\
\text { scheduling } \\
\text { and resource } \\
\text { allocation }\end{array}$ & $\begin{array}{l}* \text { Better } \\
\text { throughput. } \\
* \text { Support only } \\
50 \text { cell user }\end{array}$ \\
\hline $\begin{array}{l}\text { Utility-based } \\
\text { joint } \\
\text { uplink/downlink } \\
\text { scheduling }\end{array}$ & $\begin{array}{l}\text { Ensure utility } \\
\text { function that } \\
\text { captures the } \\
\text { quality of } \\
\text { service in } \\
\text { delay and } \\
\text { channel } \\
\text { quality }\end{array}$ & $\begin{array}{l}\text { *Low packet } \\
\text { drop ratio *High } \\
\text { power consumed }\end{array}$ \\
\hline $\begin{array}{l}\text { Propose } \\
\text { distributed cell } \\
\text { association }\end{array}$ & $\begin{array}{l}\text { Fixed } \\
\text { scheduling } \\
\text { time interval } \\
\text { to distribute } \\
\text { resources }\end{array}$ & $\begin{array}{l}* \text { Maximize data } \\
\text { rate *Inefficient } \\
\text { in highly loaded } \\
\text { network }\end{array}$ \\
\hline $\begin{array}{l}\text { Potential Aware } \\
\text { Scheduling } \\
\text { Scheme }\end{array}$ & $\begin{array}{l}\text { Uplink } \\
\text { scheduling } \\
\text { with the } \\
\text { practical } \\
\text { constraints by } \\
\text { the } \\
\text { LTE/LTE-A }\end{array}$ & $\begin{array}{l}\text { *Optimal } \\
\text { solution. *Work } \\
\text { on uplink only }\end{array}$ \\
\hline $\begin{array}{l}\text { Joint UL-DL } \\
\text { algorithm }\end{array}$ & $\begin{array}{l}\text { Resource } \\
\text { utilization for } \\
\text { better } \\
\text { (qos),but adds } \\
\text { computational } \\
\text { complexity }\end{array}$ & $\begin{array}{l}* \text { Efficiently } \\
\text { utilize carrier } \\
\text { aggregation } \\
\text { technique } \\
* \text { Computational } \\
\text { complexity }\end{array}$ \\
\hline
\end{tabular}

Table 1. Comparative Analysis of Algorithms By going through this, different algorithm focuses on different issues. In cell association problem data rate can be increase with fixed scheduling time interval, whereas in joint algorithm QoS are improved but it adds difficulties in computation.

\section{Proposed Method}

The design of interfacing of physical layer is shown in figure 3 . The physical layer interfacing consists of two core parts base station and subscriber station. The data transmission from base station to subscriber station is called as downlink data transmission. Initially the downlink queues have to initialize and apply it to downlink scheduler.

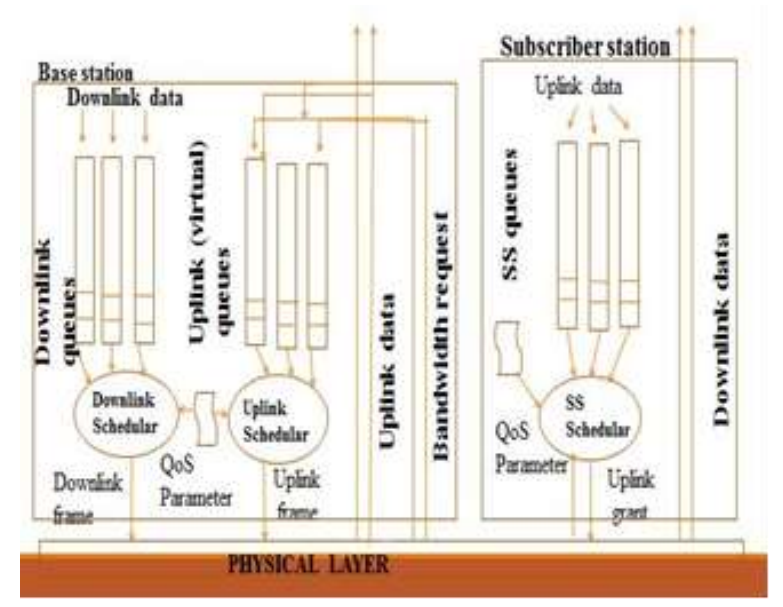

Fig.3. Architecture and Design Module

Now the downlink frame i.e. data packet will be transmit to subscriber station. Similarly the transmission from subscriber station to base station is called as uplink data transmission. After data transmission via uplink and downlink scheduling algorithm, calculate the QoS parameters. Bandwidth is an important parameter for any wireless communication system. The bandwidth utilization should be as low as possible. The process of uplink data transmission is same as that of downlink data transmission. By suitable scheduling algorithm the radio channels gets selected for data transmission and reception. The scheduling is based on the highest size of the queue. The mobile node which is having highest queue size that node will bet first priority for data transmission and reception. The important step now is to design uplink and downlink scheduling algorithm. In every time slot, the designed joint uplink and downlink scheduling algorithm is composed of three stages: prioritization stage, debt sharing stage, and power allocation stage. Loop through all connections, each connection 1 has an uplink user i sending packets to downlink user $\mathrm{j}$, and three steps are implemented-

1) Prioritization stage: Compute priority and debt for all connection. Sort connections by decreasing priority order.

2) Debt sign inspection: Debt is positive, share the debt fairly between uplink and downlink in order to achieve fair contributions to the end-to-end utility else if Debt is negative or zero, scheduler connection with minimum allowable FSR (Frame Success Rate). 
3) Power allocation: Compute uplink and downlink powers. The power values are acceptable, if they satisfy the maximum power constraints for uplink and downlink.

After design of scheduling algorithm, we implement it on our designed mobile ad-hoc network. Run the simulation and calculate quality of service parameters like throughput, delay and packet delivery ratio. The simulation parameters which are used here to design 802.11 based mobile ad-hoc network are given in table 1 . Typically all Wi-Fi based products uses $2.4 \mathrm{GHz}$ frequency since this frequency is better at traveling over walls. Basically the power at base stations is more as compared to power available at mobile station. So generally bandwidth for downlink is kept higher than the uplink. Here the downlink bandwidth is $4.5 \mathrm{Mbps}$ and for uplink is $2.5 \mathrm{Mbps}$. The mac type protocol is IEEE 802.11 i.e. Wi-Fi. Two ray ground models are beneficial when a single ground reflection of signal controls multipath effect.

\begin{tabular}{|l|l|}
\hline Parameter & Quantity \\
\hline Frequency & 2.4 GHz \\
\hline Downlink bandwidth & 4.5 Mbps \\
\hline Uplink bandwidth & 2.5 Mbps \\
\hline Channel & Wireless Channel \\
\hline Mac & 802.11 \\
\hline Propagation & Two Ray Ground \\
\hline $\begin{array}{l}\text { Downlink propagation } \\
\text { delay }\end{array}$ & $0.5 \quad$ Sec \\
\hline $\begin{array}{l}\text { Uplink propagation } \\
\text { delay }\end{array}$ & $0.5 \quad$ Sec \\
\hline Area & $600 \mathrm{~m} \mathrm{X} \mathrm{600m}$ \\
\hline Queue & Drop-Tail \\
\hline Antenna & $\begin{array}{l}\text { Omni Directional } \\
\text { Antenna }\end{array}$ \\
\hline Max packet in queue & 100 \\
\hline Number of nodes & 50 \\
\hline Routing Protocol & AOMDV \\
\hline Packet size & 1000 Bytes \\
\hline
\end{tabular}

Table 2. Simulation Parameters

The downlink and uplink propagation delay is 0.5 seconds. The simulation area is $600 \mathrm{~m}$ by $600 \mathrm{~m}$. The queue system is Drop-Tail, because when queue limit for any of the radio channel completed then only tail packets will bet dropped hence the name Drop-Tail. The antenna type used here is omnidirectional. Here the queue length is 100 . The total numbers of mobile nodes are 50. Small cell clusters are formed with separate mobile nodes and base stations. Here we are using AOMDV routing protocol since it updates its routing table only on request. So the time required choosing route from source to destination reduced and resulting the delay also reduces. The packet size is 1000 bytes

\section{Methodology}

The design of 802.11 Wi-Fi based mobile ad-hoc network consist of involvement of various steps as shown in figure 4. Initially to design MANET network initialize all the network parameters as shown in table 2 of simulation parameters section. Now next step is to create base stations and mobile stations. For that provide node number to each and every node. Provide source and destination positions to each of the mobile node. We provide different mobility's to each of the mobile node. While doing so the destination position must be within the coverage area of the network which is $600 \mathrm{~m}$ by $600 \mathrm{~m}$. After creation of mobile nodes now decide transmitter and receiver nodes. Now attach User datagram Protocol (UDP) and Constant Bit Rate (CBR) agents to all the transmitters' mobile nodes. Also attach NULL agent to all the receivers to terminate the data. Create now radio channels in between source and destination for transmission and reception of the packet data.

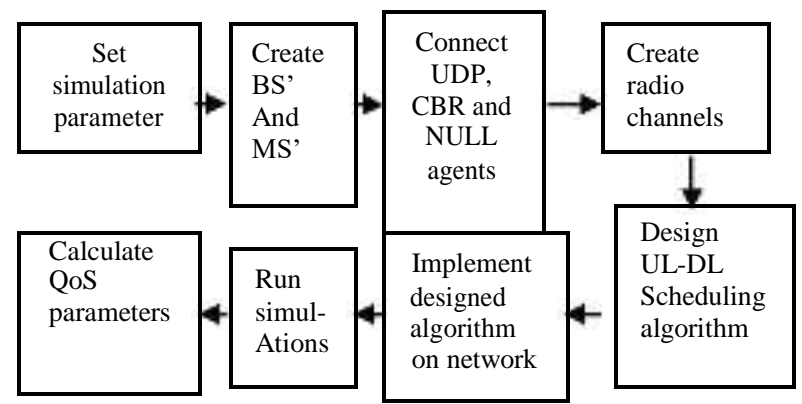

Fig.4. Block Diagram of Design of Small Cell Network in MANET

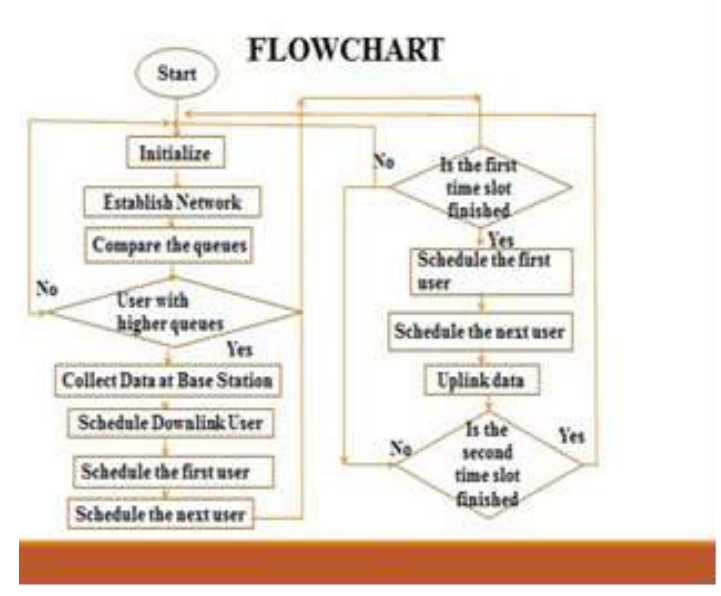

Fig.5. Flow Chart of Uplink-Downlink Scheduling

The flow chart of uplink-downlink scheduling algorithm is shown in figure 5. First of all initialize the queue limit. Establish the network. Now compare the 
queue limits of the mobile nodes those who want to transmit the data. Select the mobile user which is having highest queue size. Otherwise go to initialize step. Now collect data at base station and schedule the proper time. Schedule for first user and then for next user. If the first time slot is finished then go for first user and then next. Transmit the uplink data via radio channels. Now check the second times slot is finished or not, if yes then jump to initialization step otherwise go to the condition to check first time slot. If not done then go to initialization. Repeat these steps till transmission and reception of all data packets.

\section{Results}

The designed Wi-Fi based mobile ad-hoc network scenario consists of 50 mobile nodes. In Wi-Fi based mobile ad-hoc network packet always transfer through base station towards the receiver node. The performance parameters such as throughput, delay and packet delivery ratio are considered to evaluate the performance of such network. Generally throughput is measured in Bps,

Kbps, and Mbps.

Throughput $=$ N/30

Where $\mathrm{N}=$ Total number of packets received

Packet delivery ratio $=(\mathrm{N} / \mathrm{S}) * 100$

Where $\mathrm{N}=$ Total No. of packets received

And $\mathrm{S}=$ Total no. of packets sent

Packet delivery ratio is the total percentage of packets successfully received at the receiver. PDR is calculated as -

Packet delivery ratio $=(\mathrm{N} / \mathrm{S}) * 100$

Where $\mathrm{N}=$ Total No. of packets received And $\mathrm{S}=$ Total no. of packets sent End-to-end delay denotes to the time taken by a packet to be transmitted across a network from transmitter to receiver. End-to-end delay is measured in sec.

End-to-end delay $=$ Packet received time - Packet transmitted time

The various reading and graphs are made from our designed system. Figure 6 shows the Throughput without uplink-downlink scheduling algorithm. It represents that in particular amount of simulation time total throughput of the overall network without uplinkdownlink scheduling algorithm. Figure 7 shows delay without uplink-downlink scheduling algorithm. For any wireless communication system the end to end delay must be as low as possible. Here total simulation time is 30 Seconds. For any time total amount of packets transmitted and received calculates end to end delay as shown in figure 7 . Figure 8 shows PDR without uplink-downlink scheduling algorithm. The packet delivery ratio must be as high as possible. For our designed network without uplink and downlink scheduling algorithm the total packet delivery ratio is better than that of the existing system. Figure 8 shows that total packets successfully delivered at the receivers.

The designed uplink and downlink scheduling algorithm gives significant improvement in the quality of service parameters as shown in table2.Figure 9 shows that throughput with uplink-downlink scheduling algorithm which is more than that of the throughput without uplink and downlink scheduling algorithm. The delay which is with uplink-downlink scheduling is quite low than without scheduling algorithm which shows that by using scheduling algorithm the designed system becomes more speedy and reliable with respect to time as shown in figure 10 . Figure 11 shows that the packet delivery ratio of the system with uplink and downlink scheduling algorithm and it is better than the MANET system without scheduling algorithm.

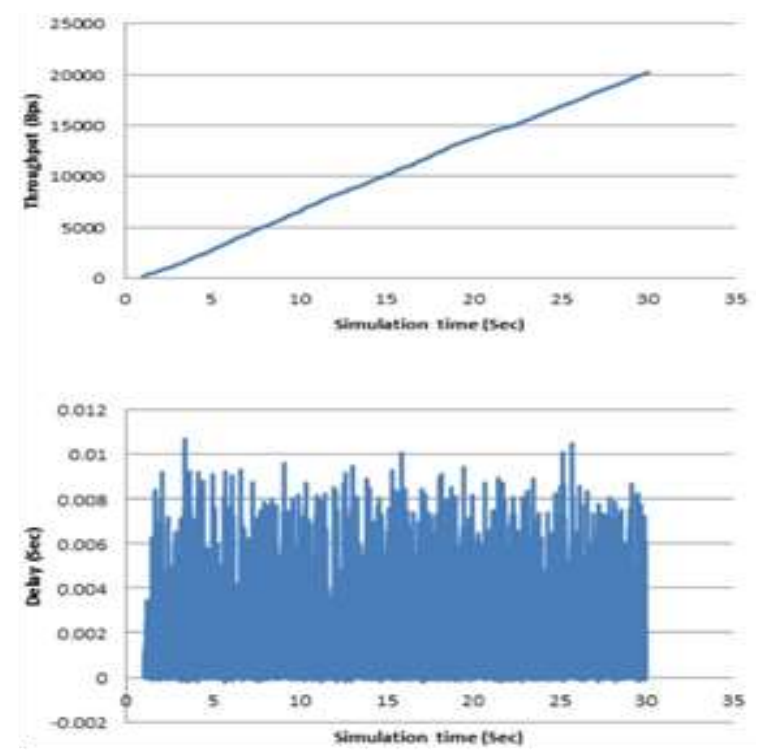

Fig.6. Throughput and Delay Without UplinkDownlink Scheduling

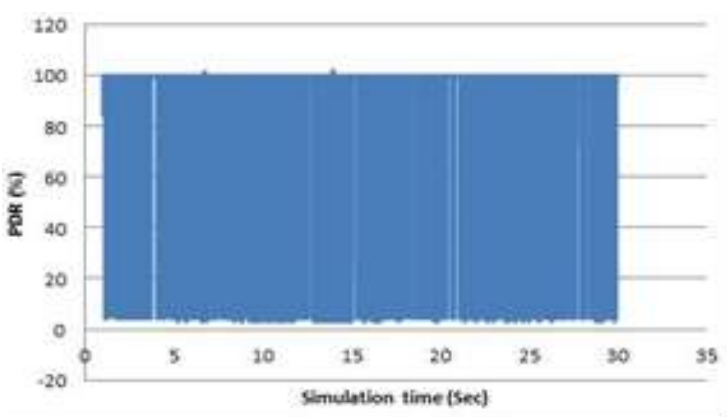

Fig.7. PDR Without Uplink-Downlink Scheduling

Table 3 shows that the comparative analysis of the quality of service parameters of the both designed systems without and with uplink-downlink scheduling 
algorithm. The average throughput of the without uplink-downlink scheduling network is $10126.03 \mathrm{Bps}$ while that of with uplink-downlink scheduling is 10634.15 Bps which shows the significant improvement in throughput and it happens only because of the availability of the radio channels in between transmitters and receivers by proper scheduling algorithm.

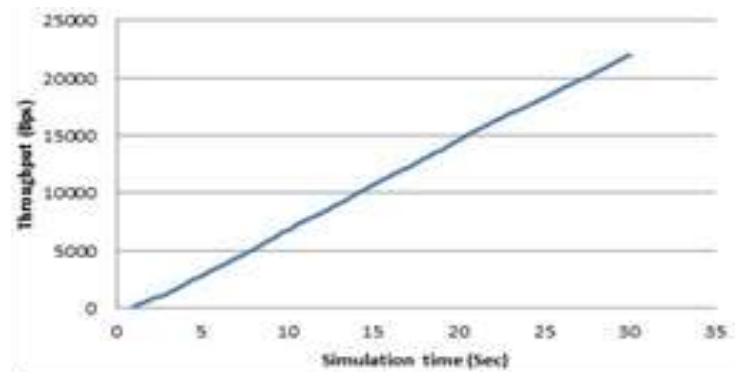

Fig.8. Throughput With Uplink-Downlink Scheduling

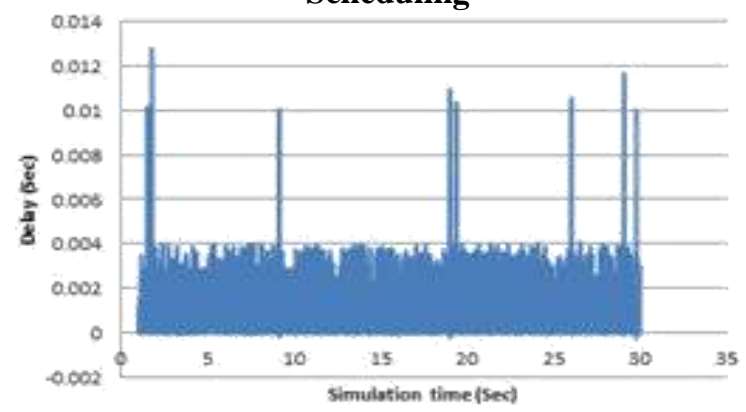

Fig.9. Delay with Uplink-Downlink Scheduling

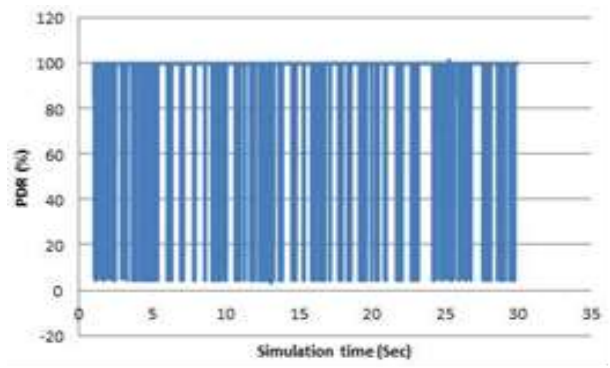

Fig.10. PDR with Uplink-Downlink Scheduling

\begin{tabular}{|l|l|c|}
\hline $\begin{array}{l}\text { Performance } \\
\text { Parameter }\end{array}$ & $\begin{array}{l}\text { Without uplink- } \\
\text { Downlink } \\
\text { scheduling }\end{array}$ & $\begin{array}{c}\text { With uplink- } \\
\text { downlink } \\
\text { scheduling }\end{array}$ \\
\hline $\begin{array}{l}\text { Average } \\
\text { Throughput } \\
\text { (Bps) }\end{array}$ & 10126.03 & 10634.15 \\
\hline $\begin{array}{l}\text { Average end to } \\
\text { end delay (Sec) }\end{array}$ & 0.0006949 & 0.0006238 \\
\hline PDR (\%) & 94.43 & 97.03 \\
\hline
\end{tabular}

Table.3. Comparative Analysis of Quality of Service Parameters

In MANET with scheduling algorithm the delay is very low as compared to without scheduling algorithm. Similarly the packet delivery ratio of
MANET with uplink and downlink scheduling algorithm is $97.03 \%$ while that of without scheduling algorithm is only $94.43 \%$.

\section{Conclusion}

By analysing the result, improvement of various parameters of Quality of Service proves that through proper scheduling, user needs of service are fulfilled. The radio channels in between transmitters and receivers are available every time and hence the probability of packet dropped gets reduced. Also due to uplink and downlink scheduling algorithm the congestion of packets stay in control and resulting that the packet deliver ratio improves the behaviour of the designed system. Overall Wi-Fi based mobile ad-hoc network deliver better performance with uplink and downlink scheduling algorithm. The researchers are continuously working on the new method of uplink and downlink scheduling. The designed algorithm can be utilized in the eNB of small cell network in $4 \mathrm{G}$ and $5 \mathrm{G}$ architecture.

\section{References}

[1] D. Chambers, "A Quick Introduction to Small Cells", October, 2013.

[2] A.M.Ghaleb, E.Yaacoub and Ayad Atiyah Abdulkafi, "QoS-Aware Joint Uplink-Downlink Scheduling in FDD LTE-Advanced with Carrier Aggregation", pp. 111-115, 2014.

[3] S. Chaudhuri, I. Baig, and D. Das (2015), "Utility based QoS aware Uplink Scheduler Scheme for LTE Small Cell Network",pp.3149-3154.

[4] A.Ragaleux,"Standard-compliant LTE-A Uplink Scheduling Scheme with Quality of Service", vol. 9545, pp. 1-15, 2017.

[5] W.Saad, Z.Dawy, and S.Sharafeddine,"A utilitybased algorithm for joint uplink / downlink scheduling in wireless cellular networks," J. Netw. Comput. Appl., vol. 35, no. 1, pp. 348-356, 2012.

[6] Hamidreza Boostanimehr, Vijay Bhargava "Joint Downlink and Uplink Aware Cell Association in HetNets with QoS Provisioning”, IEEE Transactions on Wireless Communications, 2015.

[7] A.Thyagaturu, Y.Dasthi, and M.Reisslein, "SDN Based Smart Gateways (Sm-GWs) for MultiOperator Small Cell Network Management", vol. XX, no. X, pp. 1-14, 2016.

[8] J. So, H. Jeon, and D. Ahn, "Joint Proportional Fair Scheduling for Uplink and Downlink in Wireless Networks", 2011.

[9] F. Haider et al., "Spectral-Energy Efficiency Trade-off of Cellular Systems with Mobile Femtocell Deployment", vol. 9545, pp. 1-12, 2015.

[10] A.L.I.Heidari, G.Mirjalily, and M.Agha, "Improving the Quality of Services by Scheduling Algorithms in Wimax Networks", vol. 7, no. 1, pp. 
Helix Vol. 8(5): 3781- 3786

1174-1184, 2014

[11] F. C. De Gouveia and T. Magedanz, "Quality of Service in Telecommunication Networks", Telecommunication Systems and Technologies - Vol. II.

[12] F. Limbach and M. Dueser, "Cooperative private Next- Generation Access deployment - A relational view", 2013.

[13] Chao Yang, Heng Liu and Lin Liu," Interference modelling and analysis in Heterogeneous Small-cell Networks",17th International Conference on Parallel and Distributed Computing, Applications and Technologies, 2016.

[14] Vandana Singh, Vinod Sharma,"Efficient and Fair scheduling of uplink and downlink in IEEE 802.16 OFDMA Networks", IEEE Communication Society, 2006. 